\title{
Analysis of Fractal and Energy Consumption Characteristics of Concrete under Impact Loading
}

\author{
Yutao Li $\mathbb{D}^{D}$, Faning Dang $\mathbb{D}^{\circ}$, Mei Zhou $\mathbb{D}^{\text {, }}$, and Jie Ren \\ Institute of Geotechnical Engineering, Xi'an University of Technology, Xi'an, Shaanxi 710048, China \\ Correspondence should be addressed to Faning Dang; dangfn@163.com
}

Received 18 July 2021; Revised 15 September 2021; Accepted 30 September 2021; Published 25 October 2021

Academic Editor: Peng Hou

Copyright (c) 2021 Yutao Li et al. This is an open access article distributed under the Creative Commons Attribution License, which permits unrestricted use, distribution, and reproduction in any medium, provided the original work is properly cited.

\begin{abstract}
In order to study the compressive deformation and energy evolution characteristics of concrete under dynamic loading, impact compression tests with impact velocities of 5,6 , and $7 \mathrm{~m} / \mathrm{s}$ were carried out on concrete samples with aggregate volume ratios of $0,32 \%, 37 \%$, and $42 \%$, respectively, using a split Hopkinson pressure bar test apparatus. The broken concrete pieces after destruction were collected and arranged. The fractal characteristics of fragmentation distribution of concrete specimens with different aggregate rates under impact were discussed, and the roughness of the fragment surface was characterized by the fractal dimension of the broken fragment and the crack surface energy was calculated. In addition, the analytical equation of the fractal dimension of the broken fragment and the crack surface energy was established. The relationship between the specimen energy absorption and the crack surface energy was compared and analyzed. The results show that the concrete specimens are mainly tensile split failure modes under different impact speeds. The fractal dimension, absorption energy, and crack surface energy all increase with the increase in impact speed and decrease with the increase in the aggregate rate. When the aggregate rate is different, the effective utilization rate of the absorbed energy is the largest when the aggregate content is $37 \%$. The surface energy of the crack can be used to estimate the concrete dynamic intensity.
\end{abstract}

\section{Introduction}

Concrete is the most widely used and the largest amount of building materials in civil engineering. In recent years, with the complex international situation and the rise of terrorism, as well as the development and use of various precisionguided weapons, many concrete structures are exposed to the threat of extreme external loading effects such as shock, vibration, and explosion $[1,2]$, which puts forward new requirements for the study of concrete antistrike ability and structural safety evaluation.

As a kind of multiphase composite quasibrittle material, the damage of concrete when subjected to impact loading is sudden and unpredictable, making it difficult to accurately describe its internal damage law and measure its dynamic mechanical parameters. While the nature of concrete failure is a state destabilization phenomenon driven by energy [3], the internal crack structure during damage has a statistical self-similar property. Therefore, at present, many scholars describe concrete failure characteristics and energy dissipa- tion law from the perspective of fractal theory [4] and energy $[5,6]$. Fractal dimension was mainly used to describe the crack characteristics of concrete and rock materials [7-9]. For example, Dang et al. calculated the fractal dimension of the crack surface of a concrete CT scan section using the difference box dimension and found that the fractal dimension of the crack surface can quantitatively describe the damage degree of concrete samples and better reflect the strength characteristics and crack evolution law of concrete specimens under static and dynamic tensile conditions [10]. Fang et al. established a damage variable equation of concrete based on the change law of the fractal dimension of the crack surface with load [11]. Woods et al. believed that the automatic damage assessment method was able to track the level of damage to a structural element based on the concrete crack distribution using fractal dimension analysis, and the method was shown to be able to track the nonuniform damage progression over the course of the earthquake [12]. In Konkol and Prokopski, based on the analysis of the statistical model, it has been demonstrated that the influence of 
TABLE 1: Concrete mix proportions.

\begin{tabular}{lccccc}
\hline Concrete content $(\%)$ & Cement $\left(\mathrm{kg} / \mathrm{m}^{3}\right)$ & Water content $\left(\mathrm{kg} / \mathrm{m}^{3}\right)$ & Sand $\left(\mathrm{kg} / \mathrm{m}^{3}\right)$ & Cobblestone $\left(\mathrm{kg} / \mathrm{m}^{3}\right)$ & Water reducer $\left(\mathrm{kg} / \mathrm{m}^{3}\right)$ \\
\hline 0 & 321 & 135 & 1944 & 0 & 3.2 \\
32 & 321 & 135 & 1073 & 870 & 3.2 \\
37 & 321 & 135 & 937 & 1006 & 3.2 \\
42 & 321 & 135 & 801 & 1142 & 3.2 \\
\hline
\end{tabular}

concrete fracture surface morphology (the fractal dimension $D$ ) on the prediction of the critical stress intensity factor is significant and comparable to the effect of the water/binder ratio [13]. $\mathrm{Li}$ et al. investigated the relationship between the fractal dimension of the concrete failure fragment and the dissipation energy and found that they were positively correlated $[14,15]$. Luo et al. examined the rate effect of concrete's energy absorption capacity of concrete $[16,17]$. Tan et al. discussed that the energy dissipation of concrete materials under impact loading can be divided into damage fracture energy and inertial potential energy, and the effects of four influencing factors (aggregate size, polymer-cement ratio, water-cement ratio, and cement-aggregate ratio) on energy dissipation in the specimens were explained theoretically [18]. In addition, energy analysis was also widely used in the field of energy exploitation [19-23]. The above work provides new ideas and methods for the study of the mechanism of the static and dynamic strength change of concrete structures. However, it can be found that the application of fractal dimension is mainly focused on the concrete crack morphology, and the research on the distribution characteristics of the concrete fragment after crushing and its relationship with strength is less involved; in the energy consumption analysis of concrete materials, absorption energy is often used to approximately replace the consumption energy of crack expansion for energy characterization $[24,25]$, and there is no quantitative understanding of the consumption energy of crack growth. The distribution characteristic of the concrete fragment is the macroscopic reflection of the results of its internal crack expansion. The study of the distribution of the fragment and the energy consumption of crack propagation after concrete crushing can help people better evaluate and analyze the impact strength and energy evolution law of concrete.

In this paper, the split Hopkinson bar test device with a diameter of $100 \mathrm{~mm}$ was used to carry out impact compression tests with impact velocity of 5,6 , and $7 \mathrm{~m} / \mathrm{s}$ on concrete samples with aggregate volume ratios of $0,32 \%, 37 \%$, and $42 \%$. The impact-damaged concrete fragment was sieved and the fractal dimension of the damaged fragment was calculated for each specimen, and its relationship with morphology of the fragment, impact velocity, and aggregate ratios was elaborated. Fractal dimension of the broken fragment was used to characterize the surface roughness of the broken fragment, and the analytical formula of fractal dimension of the broken fragment and crack surface energy was established; the relationship between absorbed energy, dynamic compressive strength, and crack surface energy was analyzed and compared, and the energy transfer law in concrete samples with different aggregate ratios and impact velocities was discussed. In order to distinguish the fractal dimension from the previous fractal dimension for characterizing the crack surface, the fractal dimension for characterizing the concrete fragment is called "broken fragment fractal dimension" in this paper.

\section{Experimental Program}

2.1. Preparation of Specimens. The concrete grade used for the test is C30, and the aggregate particle size is $5 \mathrm{~mm} \sim 20 \mathrm{~mm}$. According to the mix proportion in Table 1, the concrete mixture is evenly mixed and put into a rectangular mold for vibration molding. After being exposed to room temperature for $24 \mathrm{~h}$, the mold was removed and moved into a standard curing room (temperature $20 \pm 2^{\circ} \mathrm{C}$, humidity 95\%) for curing. After $28 \mathrm{~d}$, the samples were taken out and processed through core drilling, cutting, and grinding to produce cylindrical specimens with aggregate contents of 0 (pure mortar), $32 \%, 37 \%$, and $42 \%$, respectively. The bottom diameter of the samples is about $100 \mathrm{~mm}$, the height is about $50 \mathrm{~mm}$, and the parallelism difference between the two bottom surfaces is kept within $\pm 0.02 \mathrm{~mm}$.

2.2. Experimental Equipment and Loading Scheme. The impact compression tests were performed on a split Hopkinson pressure bar (SHPB) device, which mainly consists of a bullet, an input bar, a transmission bar, and a data measurement system, as shown in Figure 1, of which the pressure bar and the bullet are made of high-strength stainless steel, the length of the input bar and the transmission bar are $6000 \mathrm{~mm}$ and $4000 \mathrm{~mm}$, respectively, and the diameter is $100 \mathrm{~mm}$.

In order to solve the problem of stress uniformity during the loading process and reduce the phenomenon of high frequency oscillation of incident wave, a T2 copper sheet is pasted on the end of the input bar as a waveform shaper; meanwhile, a small amount of Vaseline lubricants is evenly applied on both ends of the concrete sample to reduce the friction effect and prevent unnecessary interference. By shaping the waveform, the original waveform collected from the test is shown in Figure 2, and it can be found that the rising phase of the incident stress wave is relatively gentle, with the rising front time of about $230 \mu \mathrm{s}$ and the acting time maintained at about $500 \mu \mathrm{s}$, which plays a positive role in slowing down the premature failure of the concrete sample and improving its stress uniformity [26].

By adjusting the air pressure to control the impact velocity, three sets of impact tests $(5,6$, and $7 \mathrm{~m} / \mathrm{s})$ of concrete samples with different aggregate rates were carried out, and three parallel samples were prepared for each group test. 


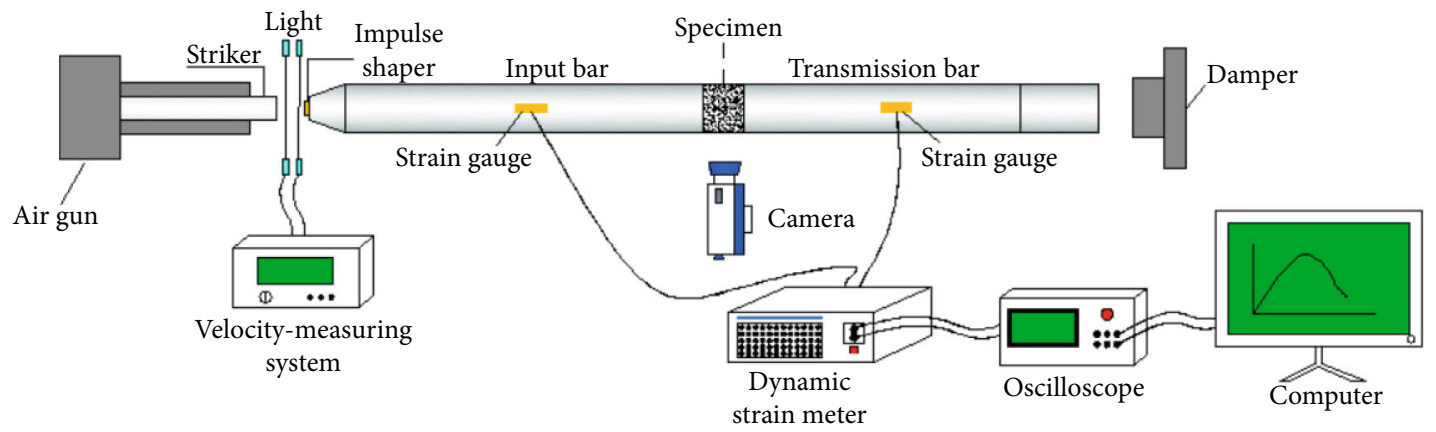

FIGURE 1: SHPB test device.

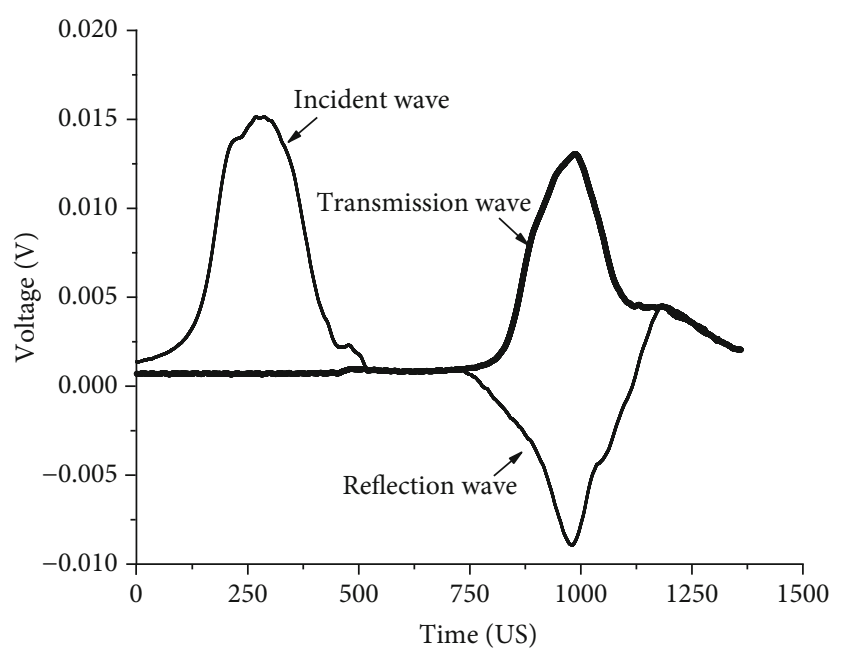

FIgURE 2: Primitive waveform in the SHPB test.

According to the basic assumption of SHPB test technology, the dynamic mechanical parameters of the specimen, such as stress, strain, and strain rate, can be calculated through the data collected by the strain gauge on the compression bar, and the calculation formulas are as follows [27].

$$
\begin{gathered}
\sigma(t)=\frac{A E}{2 A_{\mathrm{S}}}\left(\varepsilon_{\mathrm{I}}+\varepsilon_{\mathrm{R}}+\varepsilon_{\mathrm{T}}\right), \\
\varepsilon(t)=\frac{C_{0}}{L_{\mathrm{S}}} \int_{0}^{t}\left(\varepsilon_{\mathrm{I}}-\varepsilon_{\mathrm{R}}-\varepsilon_{\mathrm{T}}\right) d t, \\
\dot{\varepsilon}(t)=\frac{C_{0}}{L_{\mathrm{S}}}\left(\varepsilon_{\mathrm{I}}-\varepsilon_{\mathrm{R}}-\varepsilon_{\mathrm{T}}\right),
\end{gathered}
$$

where $\varepsilon_{\mathrm{I}}, \varepsilon_{\mathrm{R}}$, and $\varepsilon_{\mathrm{T}}$ are strain signals of incident wave, reflection wave, and transmission wave, respectively; $A$ and $A_{\mathrm{S}}$ are the cross-sectional areas of the pressure bar and the sample; $E$ and $L_{S}$ are the elastic modulus and length of the compression bar; and $C_{0}$ is the elastic wave velocity.

\section{Failure Mode and Fractal Dimension Analysis of the Failure Fragment}

3.1. Analysis of Damage Mode of Concrete Specimens. The high-speed camera was used to capture the morphologies of concrete samples during the process of impact in real time. Figure 3 shows the deformation diagram of each sample at the time of crack penetration under different impact velocities. As can be seen from the figure that under the same aggregate rate, with the increase in impact velocity, both of the number and width of axial cracks increase. When the aggregate ratio is 0 , the failure degree of the specimen is the highest and several obvious axial cracks appearing on the surface of the specimens can be observed; at the same time, accompanied by a large number of splashing fragments, the damage degree of the samples with $32 \%$ and $37 \%$ aggregate is the second, and an obvious axial cracking phenomenon can be found on the side of the specimens at the crack penetration time; when the concrete aggregate rate is $42 \%$, the damage degree is the lowest. The obvious cracks can only be found on the side of the sample at the impact velocity of $7 \mathrm{~m} / \mathrm{s}$; when the impact velocities are $5 \mathrm{~m} / \mathrm{s}$ and $6 \mathrm{~m} / \mathrm{s}$, the axial cracks on the side of the samples are less and difficult to be observed, and a small amount of concrete fragment splashes indicates that the larger the impact velocities, the more sufficient the specimen failure, the greater the aggregate ratios, and the smaller the damage degree of the samples. The increase in the impact velocity and aggregate ratio can enhance the overall impact resistance of the specimen to a certain extent and improve the deformation characteristics of the sample.

Through comparative analysis, it can be found that the failure pattern of each concrete sample is basically the same in the loading process. In the early loading stage, there are small cracks appearing on the side of the specimen and accompanied by a slight phenomenon of spalling fragments; with the progress of loading, the cracks continue to develop and expand along the axial direction until the whole sample is penetrated. As the reflection stress wave belongs to tensile wave, the concrete sample is greatly prone to cracking damage under the state of tensile stress. Combined with the comprehensive analysis of the stress state, the stress wave transmission law, and the failure pattern of the samples, the damage mode of the samples under different aggregate ratios is mainly tensile splitting failure.

3.2. Calculation and Analysis of Fractal Dimension of the Broken Fragment. Since the macroscopic failure of materials is formed by the concentration of small fracture groups, which evolve from even smaller cracks, such self-similar 


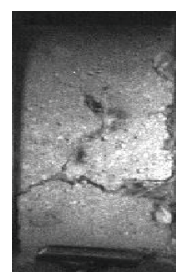

$v=7 \mathrm{~m} / \mathrm{s}$

(a) Aggregate ratio is 0

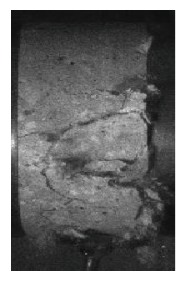

$v=5 \mathrm{~m} / \mathrm{s}$

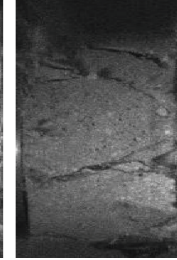

$v=5 \mathrm{~m} / \mathrm{s}$

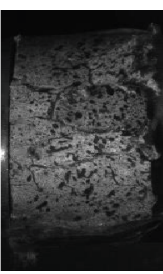

$v=6 \mathrm{~m} / \mathrm{s}$

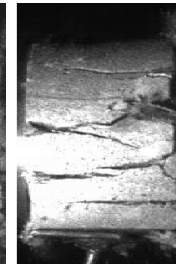

$v=6 \mathrm{~m} / \mathrm{s}$

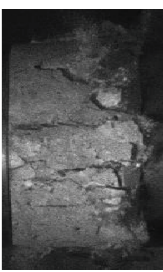

$v=7 \mathrm{~m} / \mathrm{s}$

(c) Aggregate ratio is $37 \%$
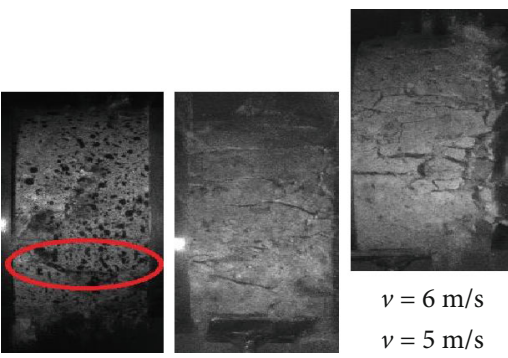

(b) Aggregate ratio is $32 \%$

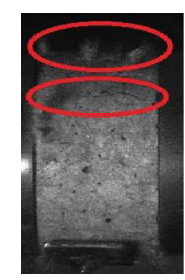

$v=5 \mathrm{~m} / \mathrm{s}$
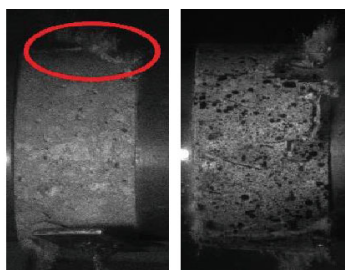

$v=6 \mathrm{~m} / \mathrm{s} \quad v=7 \mathrm{~m} / \mathrm{s}$

(d) Aggregate ratio is $42 \%$

FIGURE 3: Form of crack penetration time of concrete specimens.

behavior inevitably leads to the self-similar characteristics of the fragmentation distribution after crushing. From the basic concept of fractal dimension, it is known that if the distribution of the concrete fragment has fractal characteristics, then the expression of fractal dimension of the broken fragment is as follows:

$$
N=C x^{-D}
$$

where $N$ is the number of fragments, whose particle size is greater than $x$, i.e., the number of concrete fragments on the screen when the screen aperture is $x$; $C$ is the proportionality constant; and $D$ is the fractal dimension of the concrete failure fragment.

The mass-frequency distribution equation [28] of the fragment can be expressed as

$$
\frac{M(x)}{M}=\left(\frac{x}{x_{\mathrm{m}}}\right)^{a},
$$

where $M(x)$ is the cumulative mass of the concrete fragment with particle size which is less than $x, M$ is the total mass of the concrete fragment, and $x_{\mathrm{m}}$ is the maximum particle size of the concrete fragment.

Derivation of equations (4) and (5) is obtained: $d N \propto$ $x^{-D-1} d x$ and $d M \propto x^{a-1} d x$, while increasing the number of fragments will inevitably cause an increase in mass, i.e., $d N$ $\propto x^{-3} d M ; x^{-D-1} \propto x^{a-4}$, which gives

$$
D=3-a
$$

The crushed concrete fragment is collected and screened by standard screens of $0.5 \mathrm{~mm}, 1.0 \mathrm{~mm}, 2.0 \mathrm{~mm}, 5.0 \mathrm{~mm}$, $10 \mathrm{~mm}$, and $20 \mathrm{~mm}$. The mass of the remaining fragment in each aperture sieve was weighed by an electron scale with an accuracy of $0.01 \mathrm{~g}$, and the fractal dimension of each sample fragment was calculated by using equations (5) and (6). As an example, the double logarithmic relationship curves for the calculation of fractal dimension of the concrete breaking fragment with different aggregate rates at the impact velocity of $7 \mathrm{~m} / \mathrm{s}$ is shown in Figure 4, from which it can be found that the correlation of the fitted straight lines is so high, indicating the distribution of the broken concrete fragment after impact crushing in accordance with the fractal law.

\subsection{Relationship between Fractal Dimension and Impact} Velocity and Aggregate Rate. The relationship between impact velocity and fractal dimension of the concrete fragment is shown in Figure 5. It can be seen from the figure that the fractal dimension of the broken fragment of concrete samples with different aggregate ratios all increases with the increase in impact velocity, showing a positive linear correlation. Taking the concrete sample with an aggregate ratio of $32 \%$ as an example, comparing the relationship between concrete failure form, impact velocity $(v)$, and fractal dimension of the broken fragment (as shown in Figure 6), it can be found that the lower the loading rate, the smaller the number of fragments and the larger the particle size, the lower the crushing degree and the smaller the fractal dimension of the broken concrete fragment; the higher the loading rate, the larger the number of fragments and the smaller the particle size, the higher the crushing degree and the greater the fractal dimension of the broken fragment. This is due to the different development paths of cracks in concrete samples under the action of different impact velocities; when the impact velocity is small, the cracks will develop around the aggregate, the concrete specimens will be damaged to a lesser extent, and the fractal dimension of the damaged fragment is 


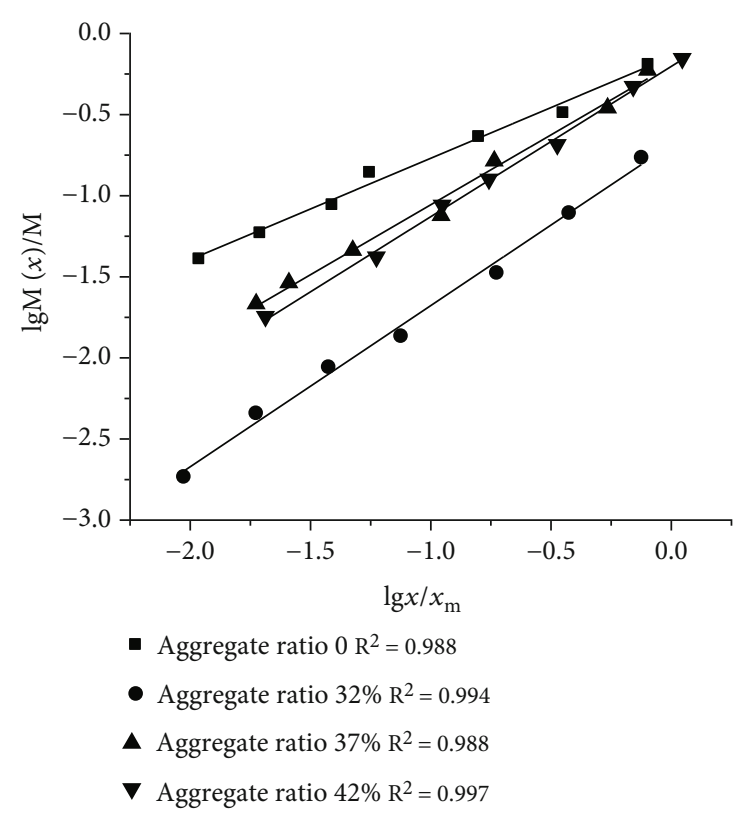

Figure 4: $\lg M(x) / M-\lg x / x_{\mathrm{m}}$ double logarithmic curves.

smaller; when the impact velocity is larger, the cracks will develop directly across the aggregate [29], and the damage of concrete samples is more complete and the fractal dimension of the broken fragment is larger.

The relationship between the fractal dimension of the broken fragment and aggregate rate is shown in Figure 7. It can be seen from the figure that, under the same impact velocity, the fractal dimension of the broken fragment decreases with the increase in the aggregate ratio, showing a linear negative correlation.

Under the same impact velocity, the fractal dimension of the damaged fragment is the largest when the aggregate ratio is 0 and the smallest at the aggregate rate of $42 \%$; when the aggregate rate is changed from 0 to $32 \%$, the fractal dimension of the broken fragment decreases obviously, about $8 \%$. Because of the concrete in the process of impact compression, the internal aggregate will form a stable skeleton structure, which can hinder and inhibit the development and expansion of cracks to a certain extent, which is conducive to the protection of the structural integrity of concrete samples, thus improving the impact resistance of concrete. When subjected to the same impact, the aggregate-free concrete samples have undergone overall fracture failure, while the aggregate samples have only undergone partial fracture failure due to the skeleton structure, resulting in a large change in the fractal dimension of the broken fragment distribution of the aggregate-free samples and the aggregate samples.

\subsection{Fractal Dimension and Surface Area of the Broken} Fragment. The specific surface area of the broken concrete specimens after impact is related to the energy absorbed and the magnitude of static and dynamic strength, and the study of the specific surface area of the broken concrete samples is beneficial to reveal the mechanism of the

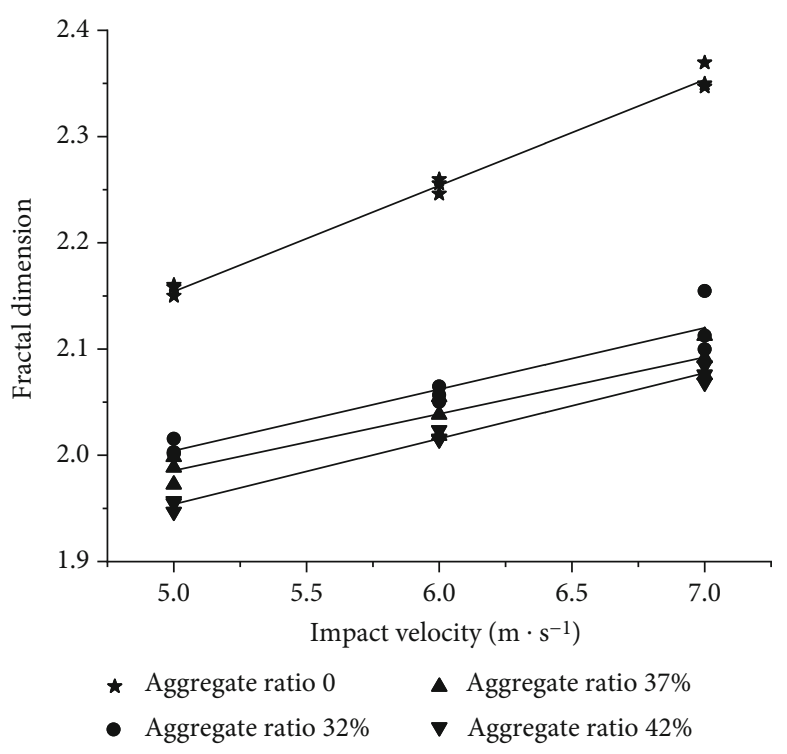

FIgURE 5: Relationship between impact velocity and fractal dimension.

improvement of the dynamic strength of concrete from the perspective of fracture mechanics. When the concrete samples are damaged, the particle size of the piece is different and the surface is uneven, so it is difficult to effectively count the total surface area of the fragment after the destruction of the samples. For the convenience of statistics, when the surface area of the concrete fragment is calculated, as the particle size of the fragment is greater than $20 \mathrm{~mm}$ and has certain shape characteristics, the calculation is carried out according to the characteristic shape of the fragment, as shown in Figure 8; when the shape of the fragment is similar to cone or cylinder, the ideal surface area of the fragment is calculated according to the corresponding surface area calculation formula; when the particle size of the fragment is less than $20 \mathrm{~mm}$, the concrete fragment is equivalent to a sphere, and the sphere diameter is taken as the average particle size of the concrete fragment on each layer screen, so that the ideal surface area of the concrete fragment can be calculated. However, due to the different aggregate ratios and impact loads, the surface roughness of the concrete samples after impact is not the same, the development and expansion path of the crack are the direct reasons for the different surface roughness of the fragment, and fractal dimension of the broken fragment is a macroscopic reflection of crack propagation and evolution in the samples. The study of Zhao et al. [15] also showed that the roughness of the fracture surface of the broken concrete fragment is related to the fractal dimension of the concrete broken fragment, so the fractal dimension of the broken fragment can be used to characterize the roughness of the broken fragment when the specimens are damaged. Then, the new surface area of the concrete fragment after impacting can be calculated with

$$
A_{\mathrm{R}}=D A_{\mathrm{I}}-A_{0},
$$




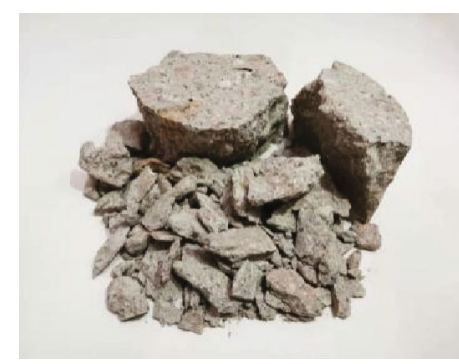

(a) $v=5 \mathrm{~m} / \mathrm{s}, D=2.01$

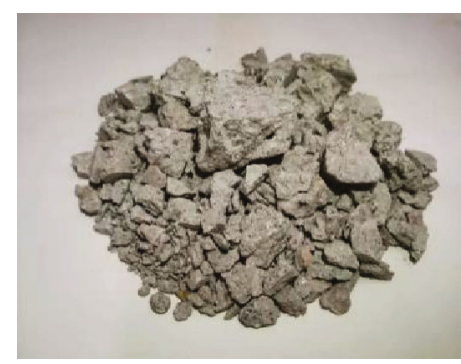

(b) $v=6 \mathrm{~m} / \mathrm{s}, D=2.06$

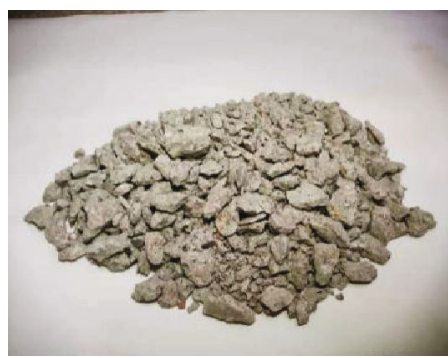

(c) $v=7 \mathrm{~m} / \mathrm{s}, D=2.16$

Figure 6: Concrete failure morphology at different impact speeds.

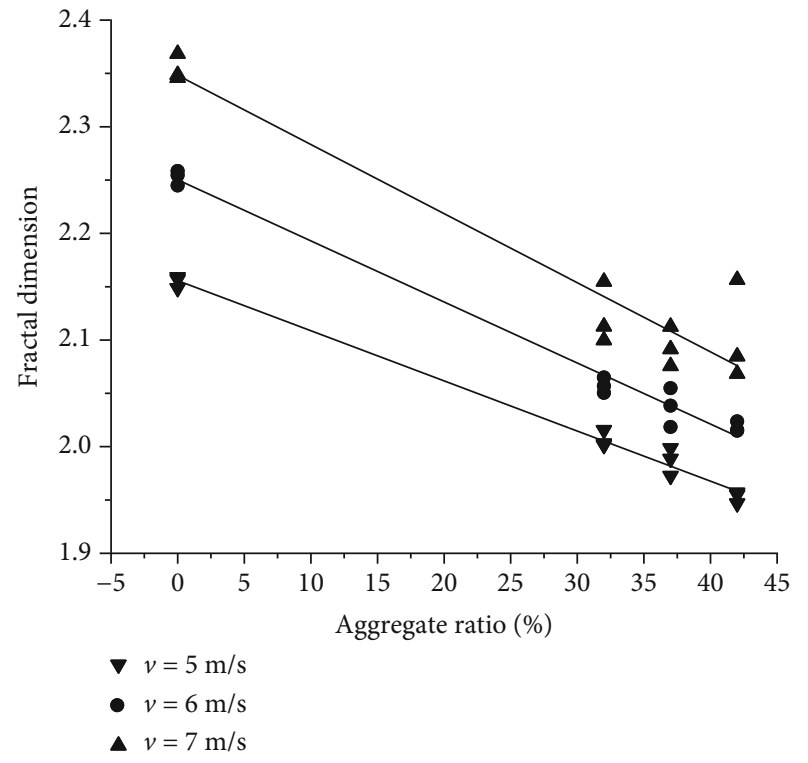

Figure 7: Relationship between aggregate rates and fractal dimension.

where $D$ is the fractal dimension of the concrete broken fragment, $A_{\mathrm{I}}$ is the ideal statistical surface area of the fragment, $A_{0}$ is the original surface area of the samples, and $A_{\mathrm{R}}$ is the actual new surface area of the fragment.

\section{Analysis of Energy Consumption Characteristics}

4.1. Energy Calculation. The energy $W_{\mathrm{I}}, W_{\mathrm{R}}$, and $W_{\mathrm{T}}$ carried by the incident, reflected, and transmitted waves during the SHPB test loading can be expressed separately as

$$
\left.\begin{array}{l}
W_{\mathrm{I}}=A E c_{0} \int \varepsilon_{\mathrm{I}}^{2}(t) d t \\
W_{\mathrm{R}}=A E c_{0} \int \varepsilon_{\mathrm{R}}^{2}(t) d t \\
W_{\mathrm{T}}=A E c_{0} \int \varepsilon_{\mathrm{T}}^{2}(t) d t
\end{array}\right\} .
$$

The energy absorbed $W_{\mathrm{S}}$ by the samples can be expressed as

$$
W_{\mathrm{S}}=W_{\mathrm{I}}-\left(W_{\mathrm{R}}+W_{\mathrm{T}}\right)
$$

In concrete samples in the occurrence of impact damage, the specimens' absorbed energy $W_{\mathrm{S}}$ mainly consists of three parts: (1) the energy dissipation of the original crack propagation and the formation of the new crack surface in the concrete samples, $W_{\mathrm{F}}$; (2) kinetic energy of the fragment splashing out of the samples during impact, $W_{\mathrm{E}}$; and (3) energy consumption during loading in the form of heat, acoustic energy, radiation, and electromagnetic energy, $W_{0}$. So, the relationship between them can be expressed as

$$
W_{\mathrm{S}}=W_{\mathrm{F}}+W_{\mathrm{E}}+W_{0}
$$

where in this paper the energy dissipated $W_{\mathrm{F}}$ to generate a new crack surface as the crack surface energy, which can be expressed as

$$
W_{\mathrm{F}}=A_{\mathrm{R}} \gamma_{\mathrm{s}}
$$

where $A_{\mathrm{R}}$ is the area of the newly formed crack surface area and $\gamma_{\mathrm{s}}$ is the energy required by the concrete material to form per unit crack area, which is the surface free energy in fracture mechanics.

According to the previous analysis of the failure mode of concrete, tensile splitting is the main failure model of the specimens under impact compression load; in order to obtain the crack surface energy of the specimens under impact compression, it is necessary to know the energy required for the formation of the unit crack area of the specimen under a splitting tension state. For this reason, SHPB splitting tensile tests were carried out on concrete samples with different aggregate ratios, since the unit crack surface energy is an inherent property of the material, only splitting tensile tests with an impact velocity of $4 \mathrm{~m} / \mathrm{s}$ were carried out on each group of samples, and the surface area of the fragment after splitting tensile failure was counted. According to the study of Ping et al., in the SHPB splitting tensile test, $W_{\mathrm{F}}$ accounts for about $95 \%$ of $W_{\mathrm{S}}$ [30], so the energy required to form a unit crack area of concrete in the splitting tensile state is calculated by using $W_{\mathrm{S}}$ as an approximate substitute for $W_{\mathrm{F}}$; the results are shown in Table 2, where $A, B, C$, and $D$ represent the aggregate volume rates of 0 , 


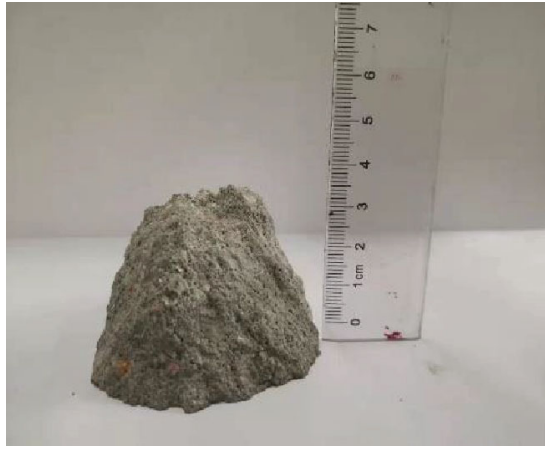

(a) Cone-like damage pattern

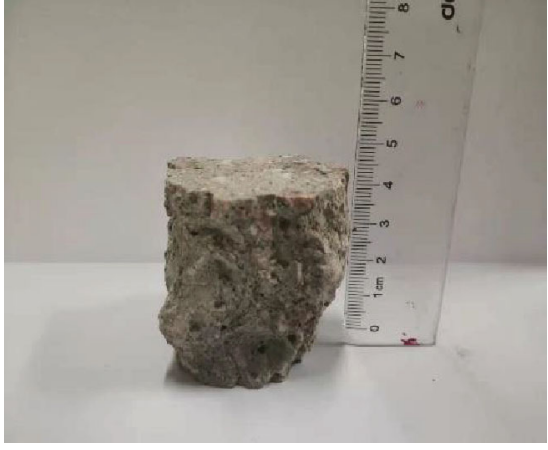

(b) Cylindrical-like damage form

FIgURE 8: Different concrete fragment destruction patterns.

$32 \%$, $37 \%$, and $42 \%$, respectively, and $T$ represents the splitting tensile test.

According to the results obtained from Table 2, the average value of the unit crack surface energy of the two groups of splitting tensile specimens was taken as their corresponding aggregate rate concrete specimens under the action of impact compression to form a unit crack surface requiring surface energy. The energy required to form a new crack surface can be obtained by combining equations (7) and (11), i.e., the relationship between the fractal dimension and the crack surface energy, as shown in

$$
W_{\mathrm{F}}=\left(D A_{\mathrm{I}}-A_{0}\right) \cdot \gamma_{\mathrm{s}} .
$$

The calculation results of relevant energy of concrete samples in the process of impact compression are shown in Table 3. $P$ in the table represents the compression test, and considering the discrete nature of the test data, two closer test data are selected for each group for analysis.

4.2. Sample Energy Absorption and Crack Surface Energy. Figure 9 shows the curve of the absorbed energy and crack surface energy of the samples with the change of aggregate rates at different impact velocities. It can be found that under the same impact velocity, both the energy absorption and crack surface energy of the sample decrease with the increase in the aggregate ratio, because when the impact velocity is constant, the magnitude of incident energy basically remains unchanged, and the reflected and transmitted energy changes with the change of the aggregate ratio of the concrete sample; when the aggregate rate increases, the sample average density and elastic modulus will increase; when the specimen is subjected to impact loading, it is more difficult to damage, which is conducive to the protection of the integrity of the concrete specimen; the better the integrity of the sample is, the bigger the wave impedance is; the reflection coefficient of the stress wave will decrease, and the transmission coefficient will increase; finally, the reflected energy of the concrete sample will decrease, the transmitted energy will increase, and the absorption energy generally decreases. At the same time, the aggregate will improve the compressive and tensile strength of the concrete specimen to a certain extent, which makes the damage of the specimen and
TABLE 2: Calculation result of unit surface energy.

\begin{tabular}{lcccc}
\hline$v\left(\mathrm{~m} \cdot \mathrm{s}^{-1}\right)$ & Specimen no. & $\begin{array}{c}\text { Fragment } \\
\text { area }\left(\mathrm{cm}^{2}\right)\end{array}$ & $\begin{array}{c}\text { Energy } \\
\text { absorption }(\mathrm{J})\end{array}$ & $\gamma_{\mathrm{s}}\left(\mathrm{J} \cdot \mathrm{cm}^{-2}\right)$ \\
\hline \multirow{2}{*}{4} & T-A-1 & 3019.11 & 41.78 & 0.014 \\
& T-A-2 & 2805.35 & 48.07 & 0.017 \\
4 & T-B-1 & 1647.82 & 38.05 & 0.023 \\
& T-B-2 & 1706.49 & 47.33 & 0.028 \\
4 & T-C-1 & 1101.38 & 36.09 & 0.033 \\
& T-C-2 & 1350.77 & 42.80 & 0.032 \\
4 & T-D-1 & 872.50 & 36.17 & 0.041 \\
& T-D-2 & 792.77 & 33.17 & 0.043 \\
\hline
\end{tabular}

the total area of the concrete fragment decrease; although the unit surface energy increases with the increase in aggregate, the relative increase in the unit surface energy is far less than the relative decrease in the total surface area of the fragment, so the crack surface energy tends to decrease with the increase in the aggregate rate.

Figure 10 shows the relationship curves of the absorption energy, crack surface energy, and impact velocity for concrete samples with different aggregate ratios, and it can be seen that the change rules of the two are basically the same; that is, both the absorption energy and crack surface energy of the samples increase with the increase in impact velocity. Because the incident energy increases with the increase in impact velocity, sample damage is so aggravating that it leads to serious mismatch phenomenon between the concrete specimen and the wave impedance of compressive bar; thus, the incident wave can only transmit the transmission wave to the transmission bar during the process of initial stress uniformity, and once the damage of the specimen occurs, it will no longer produce or only produce a small amount of transmitted wave; most of the incident wave will be reflected back to the incident bar in the form of reflection wave, while the reflected energy increment is small relative to the incident energy increment, so it can be seen from equation (10) that the absorbed energy generally increases. The more serious the damage degree of concrete samples, the more fragment produced and the larger the corresponding crack surface area, and for samples with the same 
TABLE 3: Calculation results of relevant energy during impact compression of concrete specimens.

\begin{tabular}{|c|c|c|c|c|c|c|}
\hline Specimen no. & $v\left(\mathrm{~m} \cdot \mathrm{s}^{-1}\right)$ & $W_{\mathrm{I}}(\mathrm{J})$ & $W_{\mathrm{S}}(\mathrm{J})$ & $A_{\mathrm{R}}\left(\mathrm{cm}^{2}\right)$ & $\gamma_{\mathrm{s}}\left(\mathrm{J} \cdot \mathrm{cm}^{-2}\right)$ & $W_{\mathrm{F}}(\mathrm{J})$ \\
\hline P-A-1 & \multirow{2}{*}{5} & 467.47 & 141.70 & 7349.85 & \multirow{6}{*}{0.0155} & 113.92 \\
\hline P-A-2 & & 458.15 & 142.77 & 7295.76 & & 113.08 \\
\hline P-A-3 & \multirow{2}{*}{6} & 992.92 & 441.47 & 21816.97 & & 338.16 \\
\hline P-A-4 & & 1025.22 & 455.38 & 23000.39 & & 356.51 \\
\hline P-A-5 & \multirow{2}{*}{7} & 1581.63 & 787.84 & 42249.68 & & 654.87 \\
\hline P-A-6 & & 1487.66 & 813.95 & 42870.32 & & 664.49 \\
\hline P-B-1 & \multirow{2}{*}{5} & 467.68 & 117.20 & 4043.12 & \multirow{6}{*}{0.0255} & 103.10 \\
\hline P-B-2 & & 451.36 & 103.74 & 3481.51 & & 88.78 \\
\hline P-B-3 & \multirow{2}{*}{6} & 1069.15 & 331.61 & 10187.45 & & 259.78 \\
\hline P-B-4 & & 989.97 & 337.80 & 10630.57 & & 271.08 \\
\hline P-B-5 & \multirow{2}{*}{7} & 1494.36 & 644.64 & 20830.09 & & 531.17 \\
\hline P-B-6 & & 1523.72 & 648.62 & 20475.44 & & 522.12 \\
\hline P-C-1 & \multirow{2}{*}{5} & 456.45 & 87.59 & 2517.02 & \multirow{6}{*}{0.0325} & 81.80 \\
\hline P-C-2 & & 470.37 & 76.75 & 2275.21 & & 73.94 \\
\hline P-C-3 & \multirow{2}{*}{6} & 1104.87 & 303.69 & 8515.30 & & 276.75 \\
\hline P-C-4 & & 982.18 & 311.88 & 8407.76 & & 273.25 \\
\hline P-C-5 & \multirow{2}{*}{7} & 1568.36 & 478.58 & 13069.08 & & 424.75 \\
\hline P-C-6 & & 1525.26 & 455.80 & 12762.57 & & 414.78 \\
\hline P-D-1 & \multirow{2}{*}{5} & 446.37 & 76.79 & 1521.50 & \multirow{6}{*}{0.0420} & 63.90 \\
\hline P-D-2 & & 482.35 & 72.03 & 1399.06 & & 58.76 \\
\hline P-D-3 & \multirow{2}{*}{6} & 1133.39 & 296.82 & 6367.14 & & 267.42 \\
\hline P-D-4 & & 989.61 & 288.56 & 5940.71 & & 249.51 \\
\hline P-D-5 & \multirow{2}{*}{7} & 1579.75 & 418.08 & 8630.30 & & 362.47 \\
\hline P-D-6 & & 1501.54 & 396.69 & 8111.14 & & 340.67 \\
\hline
\end{tabular}

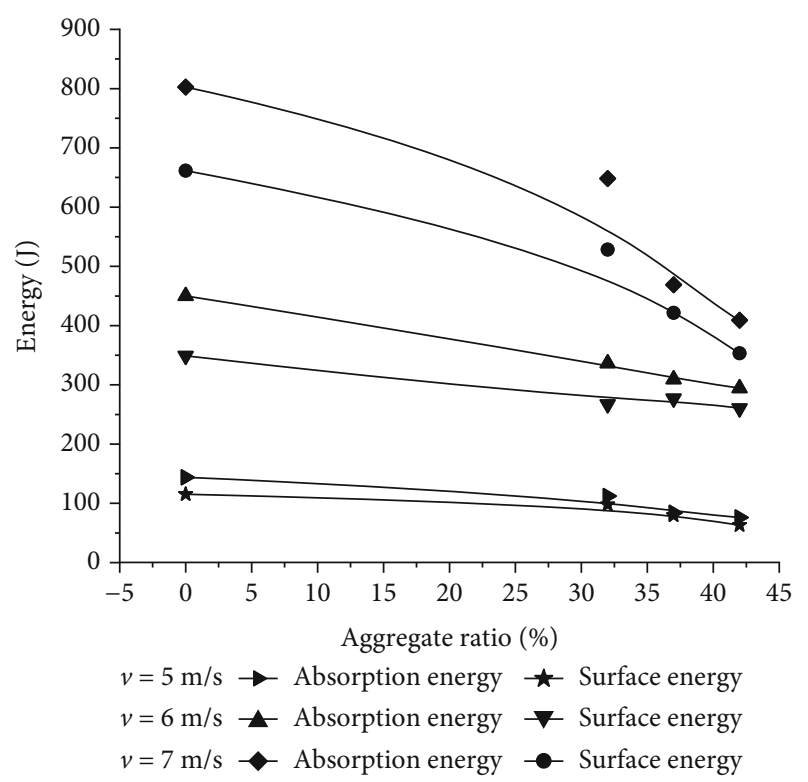

FIGURE 9: The relationship between the absorption energy and crack surface energy of the specimens and the aggregate rate.

aggregate rate, since its unit crack surface energy is constant, then the larger the surface area of the fragment, the greater the crack surface energy. In addition, it can also be seen that the absorbed energy of the sample is always higher than the surface energy of the crack, because when subjected to impact, not only is the energy absorbed by the sample used for crack expansion to form the crack surface energy but also part of the energy is dissipated in the external environment in the form of fragment splash energy, electromagnetic energy, heat energy, etc.

The relationship between sample absorption energy and crack surface energy can also be seen from Figures 9 and 10 . First of all, the change rules of the two are consistent, and both decrease with the increase in the aggregate ratio. Secondly, they all increase with the increase in impact velocity, which is due to the total surface area of the concrete fragment increasing with the increase in impact velocity. Third, the difference between absorbed energy and crack surface energy increases with the increase in impact velocity; that is, the difference between the two is smaller when the impact velocity is small, especially in quasistatic loading when the absorbed energy of the specimen is basically converted into crack surface energy.

4.3. Effective Utilization Rate of Energy Absorption of the Sample. In order to further investigate the relationship between the sample absorbed energy and crack surface energy, it is necessary to analyze the difference between them. The effective utilization rate of absorption energy $\alpha$ of the concrete sample is defined as the ratio of crack surface 


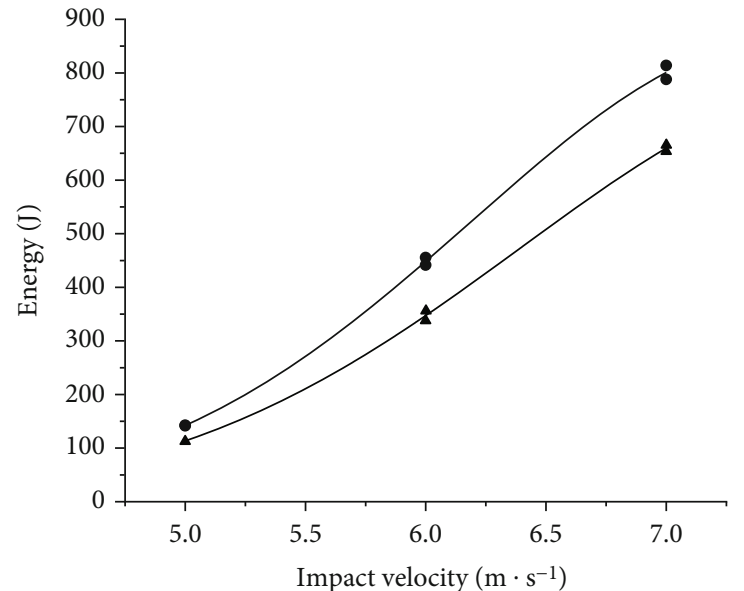

- Absorption energy

- Surface energy

(a) Aggregate ratio 0

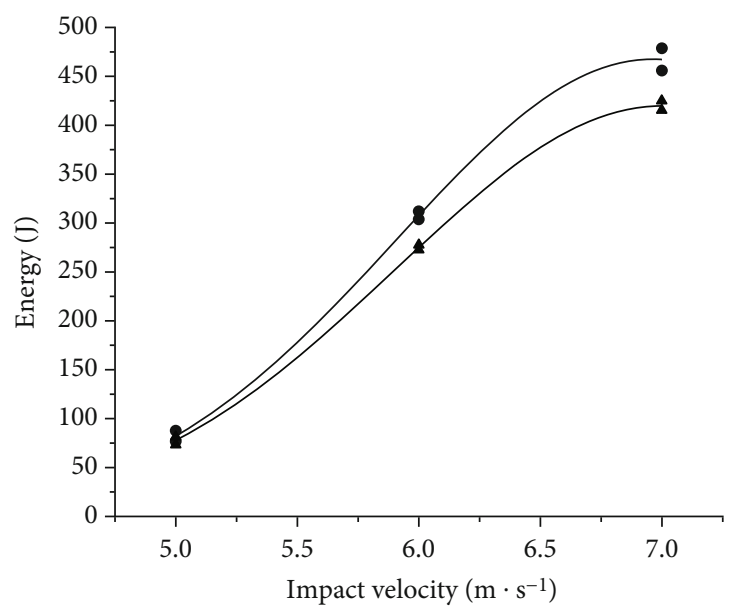

- Absorption energy

- Surface energy

(c) Aggregate ratio $37 \%$

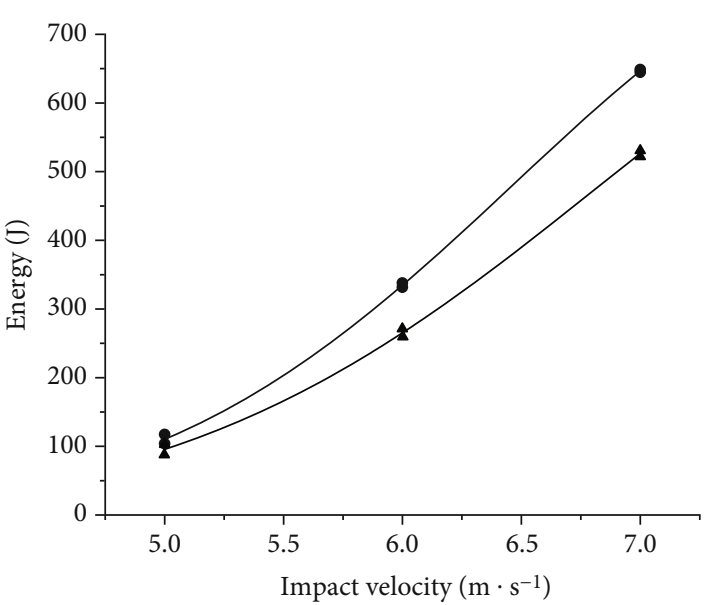

- Absorption energy

- Surface energy

(b) Aggregate ratio 32\%

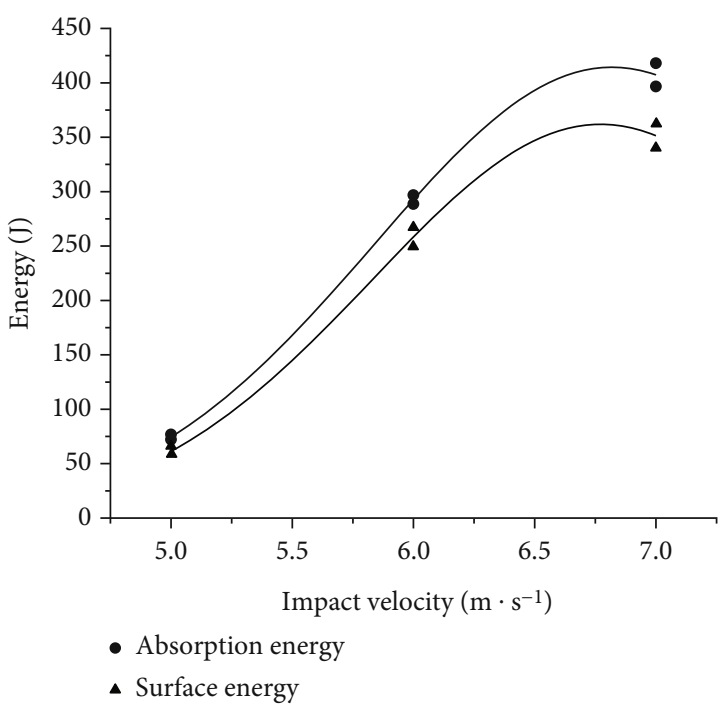

(d) Aggregate ratio $42 \%$

FIgURE 10: The relationship between the absorbed energy and crack surface energy of the specimens and the impact velocity.

energy and absorption energy of the sample, i.e.,

$$
\alpha=\frac{W_{\mathrm{F}}}{W_{\mathrm{S}}} .
$$

Figure 11 shows the relationship curve between the effective energy absorption utilization rate of concrete samples with different aggregate rates and the change of the strain rate.

It can be found from the figure that, within a certain strain rate range, the effective energy absorption utilization rate of samples with different aggregate rates basically remains unchanged. When the aggregate rate is 0 and the strain rate is between 65 and $155 \mathrm{~s}^{-1}, \alpha$ is about $79.9 \%$; when the aggregate rate is $32 \%$ and the strain rate is between 60 and $125 \mathrm{~s}^{-1}, \alpha$ is about $82.5 \%$; when the aggregate rate is $37 \%$ and the strain rate is between 50 and $80 \mathrm{~s}^{-1}, \alpha$ is about
$91.4 \%$. When the aggregate rate is $42 \%$ and the strain rate ranges from 35 to $70 \mathrm{~s}^{-1}, \alpha$ is about $85.7 \%$. Because the strain rate is a measure to characterize the deformation speed of the material, when the concrete specimen is subjected to impact loading, the internal crack expansion speed and the deformation speed of the specimen affect each other; when the deformation speed is within a certain range, it can make the specimen absorb energy and crack surface energy in a relatively balanced state; that is, the ratio of crack surface energy to absorbed energy of the specimen remains basically the same.

Figure 12 shows the relationship curve of the effective utilization rate of energy absorption of samples with the change of the aggregate rate. It can be seen from the figure that when the impact velocity is $5 \mathrm{~m} / \mathrm{s}$, the effective utilization rate of energy absorption of the samples increases first and then decreases with the increase in the aggregate rate. When the aggregate rate is $0,32 \%, 37 \%$, and $42 \%$, the mean 


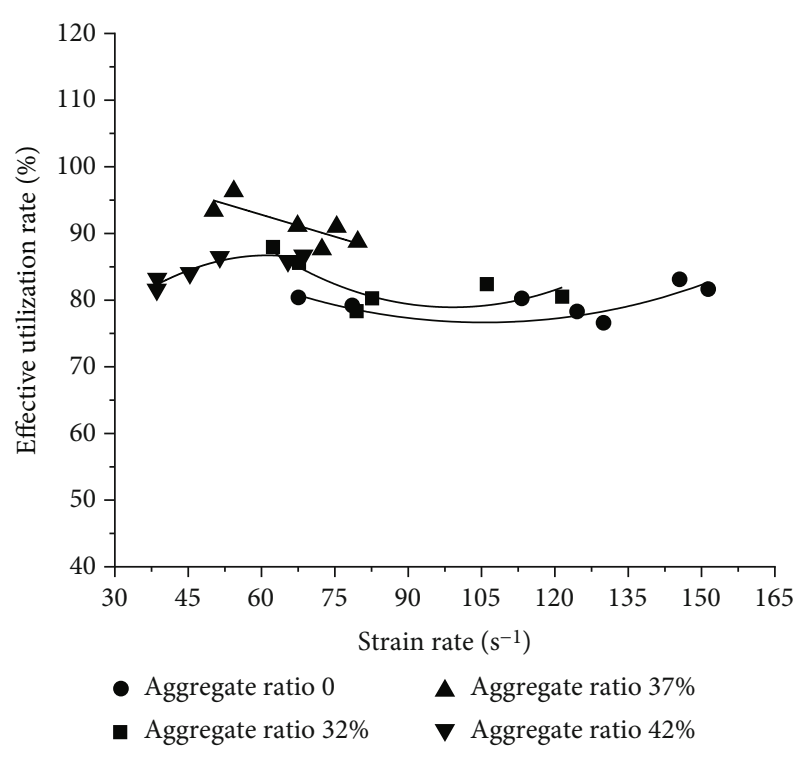

FIGURE 11: The relationship between the effective utilization rate of energy absorption of specimens and the strain rate.

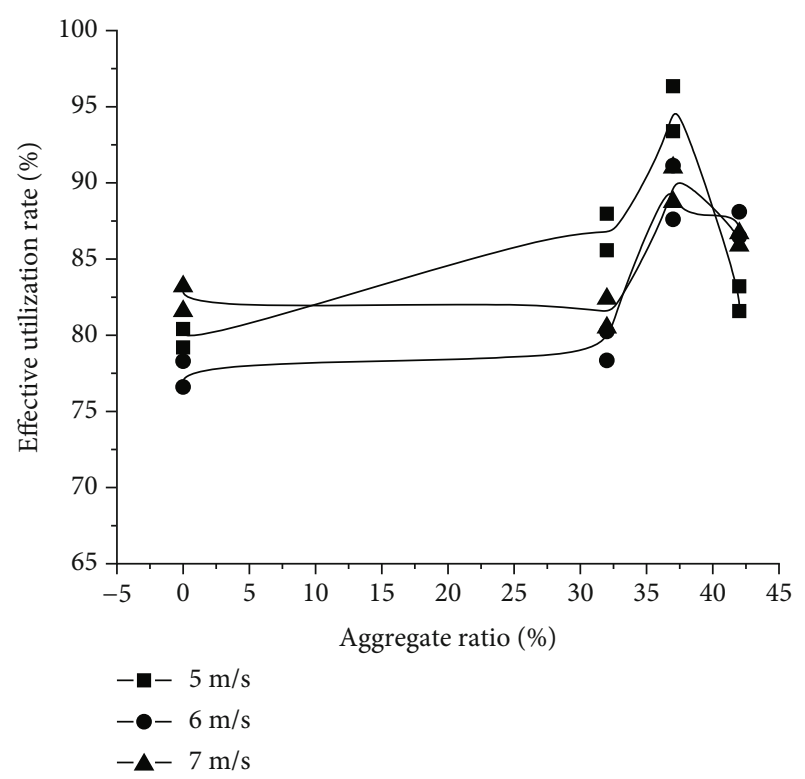

FIGURE 12: The relationship between the effective utilization rate of energy absorption of the specimens and the aggregate rates.

values of $\alpha$ are about $79.8 \%, 86.8 \%, 94.9 \%$, and $82.4 \%$, respectively; when the impact velocity is 6 and $7 \mathrm{~m} / \mathrm{s}$ and the aggregate ratio is 0 and $32 \%, \alpha$ basically remains unchanged with an average of about $78.4 \%$ and $81.9 \%$, respectively, and when the aggregate ratio is $37 \%, \alpha$ suddenly increases with an average of $89.4 \%$ and $89.9 \%$, respectively; when the aggregate ratio is $42 \%, \alpha$ gradually decreases with an average of $88.3 \%$ and $86.3 \%$, respectively. It can be seen that under different impact velocities, although the effective utilization rate of absorbing energy of samples has no uniform change rule when the aggregate rate is 0 and $32 \%$, they all reach the peak height when the aggregate rate is $37 \%$ and

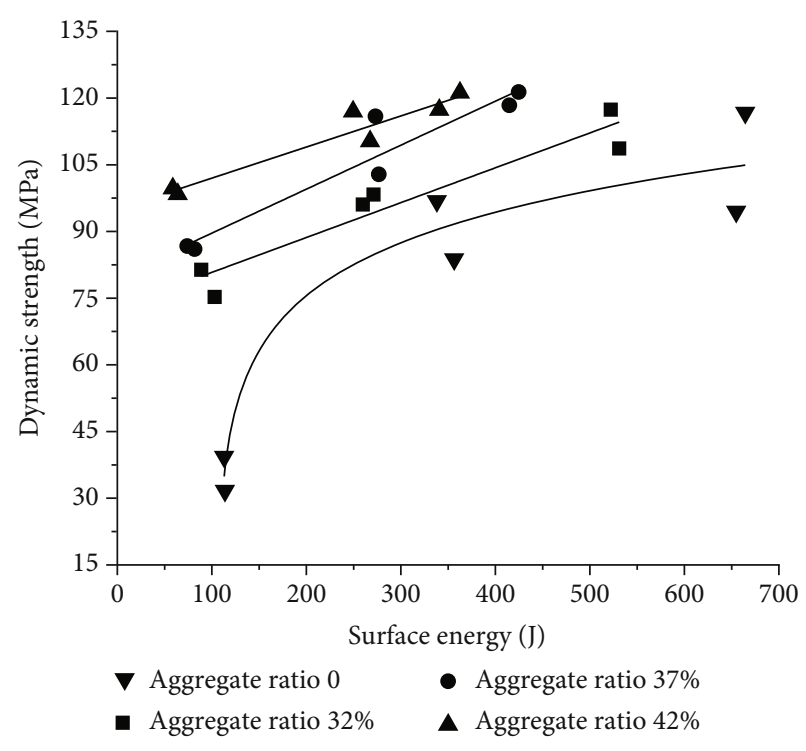

FIgURE 13: Crack surface energy and dynamic compressive strength.

show a downward trend when the aggregate rate is $42 \%$, indicating that the aggregate rate of $37 \%$ is more conducive to the effective utilization rate of energy absorption of concrete.

4.4. Sample Dynamic Strength and Crack Surface Energy. The relationship between crack surface energy of concrete and dynamic compressive strength is shown in Figure 13. When the aggregate ratio is $0,32 \%, 37 \%$, and $42 \%$, the fitting relationship between the crack surface energy of each concrete and its dynamic compressive strength is, respectively, corresponding to equations (14) and (17). It can be clearly seen that without the aggregate, the two show a nonlinear relationship of $y=a \ln (x-b)$; with the aggregate, the two show a linear relationship of $y=a+b x$.

$$
\begin{aligned}
& \sigma=16.58 \ln \left(W_{\mathrm{F}}-101.24\right) \quad\left(R^{2}=0.92\right), \\
& \sigma=72.95+0.08 W_{\mathrm{F}} \quad\left(R^{2}=0.89\right), \\
& \sigma=79.72+0.10 W_{\mathrm{F}} \quad\left(R^{2}=0.89\right), \\
& \sigma=92.95+0.07 W_{\mathrm{F}} \quad\left(R^{2}=0.90\right) .
\end{aligned}
$$

The aggregate will affect the crack development and propagation path of concrete cracking and then affect the crack surface energy and dynamic compressive strength. When there is aggregate in the concrete sample, the aggregate and mortar will form a special bonding surface (interface), and the tensile and pressure mechanical properties of the interface are lower than those of the aggregate and mortar; when the concrete specimen is subjected to impact loading, some cracks develop and expand along the interface and the development path of the crack and the failure pattern of the concrete fragment depend on the amount and location of the aggregate to some extent; when the concrete sample is damaged by impact without the aggregate, the crack will 
expand randomly and irregularly inside the specimen, which may be the reason for the different fitting relationships between crack surface energy and dynamic compressive strength of the sample with and without the aggregate.

\section{Conclusions}

In this paper, impact compression tests at 5,6 , and $7 \mathrm{~m} / \mathrm{s}$ are carried out on concrete samples with aggregate ratios of 0 , $32 \%, 37 \%$, and $42 \%$ by conducting the SHPB test. The main findings can be summarized as follows:

(1) The failure law of concrete samples at different impact velocities is basically the same; in the early stage of loading, small cracks appear along the axial direction of the samples; accompanied by a slight fragment spalling phenomenon, with the progress of loading, cracks continue to develop and expand along the axial direction until running through the whole sample. Combined with the comprehensive analysis of the stress state, stress wave transmission law, and failure mode of the samples, the tensile splitting failure is mainly the damage pattern

(2) The loading rate is low, the number of broken concrete pieces is small, and the particle size is large; the breaking degree is low, and the fractal dimension of the broken concrete piece is small; the loading rate is high, the number of concrete fragments is large, and the particle size is small; the breaking degree is high, and the fractal dimension of the broken fragment is large; at the same impact velocity, the fractal dimension of the broken fragment decreases with the increase in the aggregate ratio

(3) Fractal dimension of the broken fragment can not only describe the degree of damage of concrete but also better characterize the roughness of the fragmentation surface. The relationship expression among crack surface energy, absorption energy, and fractal dimension of the broken fragment is established. The absorbed energy and crack surface energy of the specimen increase with the increase in impact velocity and decrease with the increase in the aggregate ratio

(4) For the same aggregate rate specimen, the effective utilization rate of energy absorption basically remained unchanged within a certain strain rate range; the energy absorption efficiency of samples with different aggregate ratios was different, and the maximum value was reached when the aggregate ratio was $37 \%$

(5) Under impact loading, cracks in concrete samples without the aggregate develop in disorder, while cracks in concrete specimens with the aggregate develop along the interface between the aggregate and mortar. The different development of crack paths may be the reason for the different fitting relationships between dynamic compressive strength and crack surface energy of samples with and without the aggregate. Equations (14) and (17) can be used to estimate the dynamic strength of concrete

\section{Data Availability}

The data (fractal dimension, absorption energy, crack surface energy, and aggregate rate) used to support the findings of this study are included within the article.

\section{Conflicts of Interest}

The authors declare that they have no known competing financial interests or personal relationships that could have appeared to influence the work reported in this paper.

\section{Acknowledgments}

This paper was supported by the National Natural Science Foundation of China (Nos. 51679199 and 51979225), the Ministry of Water Resources Public Welfare Industry Research Project (No. 201501034-04), and Shaanxi Key Laboratory of Science and Technology Innovation Project (No. 2014SZS15-Z01).

\section{References}

[1] C. Fallon and G. J. Mcshane, "Impact mitigating capabilities of a spray-on elastomer coating applied to concrete," International Journal of Impact Engineering, vol. 128, pp. 72-85, 2019.

[2] V. I. Kolchunov and N. B. Androsova, "Influence of the structure of the cross-section of load-bearing structures on their deformation during emergency actions," IOP Conference Series Materials Science and Engineering, vol. 463, no. 3, article 032067, 2018.

[3] H. P. Xie, R. D. Peng, Y. Ju, and H. W. Zhou, "On energy analysis of rock failure," Chinese Journal of Rock Mechanics and Engineering, vol. 24, no. 15, pp. 2604-2608, 2005.

[4] L. Zhang, F. N. Dang, W. H. Ding, and L. Zhu, "Comparative study on damage process of concrete subjected to uniaxial tensile and compression loads based on CT test and improved differential box counting method," Construction and Building Materials, vol. 285, p. 122693, 2021.

[5] J. Ren, F. N. Dang, and H. Wang, "Enhancement mechanism of the dynamic strength of concrete based on the energy principle," Materials, vol. 11, no. 8, p. 1274, 2018.

[6] L. Zhu, F. N. Dang, Y. Xue, K. Jiao, and W. H. Ding, "Multivariate analysis of effects of microencapsulated phase change materials on mechanical behaviors in light-weight aggregate concrete," Journal of Building Engineering, vol. 42, p. 102783, 2021.

[7] P. Hou, X. Liang, F. Gao, J. B. Dong, J. He, and Y. Xue, “Quantitative visualization and characteristics of gas flow in $3 \mathrm{D}$ porefracture system of tight rock based on Lattice Boltzmann simulation," Journal of Natural Gas Science and Engineering, vol. 89, no. 4, p. 103867, 2021.

[8] P. Hou, X. Liang, Y. Zhang, J. He, F. Gao, and J. Liu, "3D multiscale reconstruction of fractured shale and influence of fracture morphology on shale gas flow," Natural Resources Research, vol. 30, no. 3, pp. 2463-2481, 2021. 
[9] X. Liang, P. Hou, Y. Xue, X. J. Yang, F. Gao, and J. Liu, “A fractal perspective on fracture initiation and propagation of reservoir rocks under water and nitrogen fracturing," FractalsComplex Geometry Patterns and Scaling in nature and Society, vol. 29, no. 7, Article ID 2150189, 26 pages, 2021.

[10] F. N. Dang, J. Y. Fang, and W. H. Ding, "Fractal comparison research of fracture of concrete samples under static and dynamic uniaxial tensile using CT," Journal of Rock Mechanics and Engineering, vol. 34, no. S1, pp. 2922-2928, 2015.

[11] J. Y. Fang, F. N. Dang, and W. H. Ding, "Fractal research on failure process of concrete under dynamic uniaxial compression based on CT scan graphics," Earthquake Engineering and Engineering Dynamics, vol. 35, no. 2, pp. 208-214, 2015.

[12] J. E. Woods, Y. S. Yang, P. C. Chen, T. L. David, and E. Jeffrey, "Automated crack detection and damage index calculation for RC structures using image analysis and fractal dimension," Journal of Structural Engineering, vol. 147, no. 4, p. 04021019, 2021.

[13] J. Konkol and G. Prokopski, "Fracture toughness and fracture surfaces morphology of metakaolinite-modified concrete," Construction \& Building Materials, vol. 123, pp. 638-648, 2016.

[14] Y. Li, Y. Zhai, X. Liu, and W. Liang, "Research on fractal characteristics and energy dissipation of concrete suffered freezethaw cycle action and impact loading," Materials, vol. 12, no. 16, p. 2585, 2019.

[15] X. Zhao, S. L. Xu, and Q. H. Li, "Fractal characteristics of firedamaged ultrahigh toughness cementitious composite after impact loading," China Civil Engineering Journal, vol. 52, no. 2, pp. 44-55, 2019.

[16] X. Luo, J. Y. Xu, E. L. Bai, and W. Li, "Research on the dynamic compressive test of highly fluidized geopolymer concrete," Construction \& Building Materials, vol. 48, pp. 166-172, 2013.

[17] N. Lv, H. B. Wang, Q. Zong, M. X. Wang, and B. Chen, "Dynamic tensile properties and energy dissipation of highstrength concrete after exposure to elevated temperatures," Materials, vol. 13, no. 23, p. 5313, 2020.

[18] Y. Tan, Y. Cheng, J. Liu, G. Li, and Y. Zhang, "Experimental study of the dynamic mechanical properties of highperformance equal-sized-aggregate concrete," Journal of Materials in Civil Engineering, vol. 33, no. 2, p. 04020463, 2021.

[19] Y. Xue, J. Liu, F. N. Dang, X. Liang, S. H. Wang, and Z. Y. Ma, "Influence of $\mathrm{CH}_{4}$ adsorption diffusion and $\mathrm{CH}_{4}$-water twophase flow on sealing efficiency of caprock in underground energy storage," Sustainable Energy Technologies and Assessments, vol. 42, p. 100874, 2020.

[20] Y. Xue, P. G. Ranjith, F. N. Dang et al., "Analysis of deformation, permeability and energy evolution characteristics of coal mass around borehole after excavation," Natural Resources Research, vol. 29, no. 5, pp. 3159-3177, 2020.

[21] Y. Xue, T. Teng, F. Dang, Z. Ma, and H. Xue, "Productivity analysis of fractured wells in reservoir of hydrogen and carbon based on dual-porosity medium model," International Journal of Hydrogen Energy, vol. 45, no. 39, pp. 20240-20249, 2019.

[22] Y. Xue, J. Liu, P. G. Ranjith, L. Xin, and S. H. Wang, "Investigation of the influence of gas fracturing on fracturing characteristics of coal mass and gas extraction efficiency based on a multi-physical field model," Journal of Petroleum Science and Engineering, vol. 206, p. 109018, 2021.

[23] J. Liu, Y. Xue, W. Chen, P. Hou, S. Wang, and X. Liang, "Variational phase-field model based on lower-dimensional inter- facial element in FEM framework for investigating fracture behavior in layered rocks," Engineering Fracture Mechanics, vol. 255, p. 107962, 2021.

[24] L. Ma, Z. Li, J. Liu, L. Duan, and J. Wu, "Mechanical properties of coral concrete subjected to uniaxial dynamic compression," Construction and Building Materials, vol. 199, pp. 244-255, 2019.

[25] Y. Qiao, H. Wang, I. L. Ca, W. Zhang, and B. Yang, "Influence of low temperature on dynamic behavior of concrete," Construction and Building Materials, vol. 115, pp. 214-220, 2016.

[26] Q. Y. Ma and C. H. Gao, "Energy absorption and fractal characteristics of basalt fiber-reinforced cement- soil under impact loads," Rock and Soil Mechanics, vol. 39, no. 11, 2018.

[27] S. Wang, L. Dong, and J. Zhou, "Influence of early age on the wave velocity and dynamic compressive strength of concrete based on split Hopkinson pressure bar tests," Shock and vibration, vol. 2018, Article ID 8206287, 8 pages, 2018.

[28] M. C. He, G. X. Yang, J. L. Miao, X. N. Jia, and T. T. Jiang, "Classification and research methods of rock burst experimental fragments," Chinese Journal of Rock Mechanics and Engineering, vol. 28, no. 8, pp. 1521-1529, 2009.

[29] F. N. Dang, K. Jiao, and F. Pan, "Investigation on concrete dynamic bending intensity and limit flexural intensity," Explosion and Shock Waves, vol. 36, no. 3, pp. 422-428, 2016.

[30] Q. Ping, Q. Y. Ma, and P. Yuan, "Energy dissipation analysis of stone specimens in SHPB tensile tests," Journal of Mining \& Safety Engineering, vol. 30, no. 3, pp. 401-407, 2013. 